\title{
Gender Related Stereotypes and their impact on Leadership
}

\author{
Amber Raza
}

\begin{abstract}
Gender stereotypes and transformational leadership can be viewed through the lens of implicit leadership theories (ILTS). Implicit theory suggests that one's idea of what effective leadership is has a large impact on leadership ratings and as a result, leadership questionnaire often yield biased ratings of leadership behavior (Rush, Thomas and Lord, 1977). Maher (1997) has examined gender related stereotypes and concluded that men may have similar ILTs for male and female leaders but women may have different ILTS for both genders. Female leaders attribute their use of relational styles to their transformational leadership whereas men feel that their power and direct styles contribute to transformational leadership (Komives, 1991). This may suggest that women have ILTs of transformational leadership that include more developmental and nurturing behaviors than men. This paper will highlight the various traits associated with male and female leaders and its impact on the workplace. Most research journals tend to focus on quantitative approach. However, this paper explores the theory of transformational leadership through a case study approach. While these interviews and accounts may not be generalizable, however they could provide insights to the already conducted quantitative work.
\end{abstract}

Keywords: Gender stereotypes, leadership ratings, power styles, transformational leadership

\section{Introduction}

Leadership is quite a popular topic today in both psychology and business, with organizations spending enormous amounts of money each year on the identification, development, and training of leaders in the hope that doing so will result in consistently strong leadership and sustained organizational success.

The present study focuses primarily on two topics in the ambit of leadership: transformational leadership and implicit leadership theories. The leadership theories can be classified into three primary types: those theories that focus on leaders, those that focus on situational and follower influences on leaders and those that focus on interactions between leaders and followers.

Transformational leadership is an all-encompassing approach that can be used to describe a wide range of leadership processes, from specific intentions to influence followers on a one-to-one level to a broad attempt to influence organizations and even

Amber Raza is Assistant Professor, College of Management Sciences, PAF Kiet, Karachi, amber@pafkiet.edu.pk 
entire cultures.

\section{Transformational leader}

A transformational leader plays a pivotal role in precipitating change, followers and leaders are inextricably bound together in the transformational process (Bass and Avolio, 1990a).

Transformational leaders are recognized as change agents who are good role models. They create and articulate a clear vision for the organization; empower followers to achieve higher standards; act in ways that make others want to trust them; and give meaning to organizational life (Bass and Avolio, 1990b).

Transformational leadership (Bass, 1985; Burns, 1978) encompasses many of the ideas of charismatic leadership, while expanding it to include other ways in which leaders would seek to change and transform individuals to accomplish more than is normally expected so that they can 'reach their fullest potential.' These theories hold great intuitive appeal for organizations, and they bring followers to the forefront, as it is their needs, values, and morals which leaders must connect with and appeal to in order to affect change.

However, both transformational and charismatic leaderships have been criticized for being conceptually unclear and not easily developed or taught, much in the same way trait theories have been criticized (Bryman, 1992).

Charisma's relationship to transformational leadership (if any) is also a major source of disagreement among researchers, as some view charisma as an important facet of transformational leadership while others see it as an overlapping but unnecessary criterion. For instance, in his initial conceptualization of transformational leadership, Bass (1985) listed charisma among his seven leadership factors and survey research with the Multifactor Leadership Questionnaire (MLQ). Bass and Avolio, 2000) seems to provide some evidence of this. However, at least some field studies appear to contradict this, showing instead that there is a tendency for people to associate charisma infrequently or not at all with their transformational leaders (Yukl, 1999).

Further complicating the issue, Bass has most recently stated that for most applications (assessment, counselling, and training purposes) it might be more useful to view higherorder factors (such as transformational leadership) and their associated lower-order factors (such as charisma and intellectual stimulation) as separate constructs, in order to increase one's chances of observing a larger range of leadership styles across cultures and organizations (Avolio, Bass, and Jung, 1999; Bass, 1988).

This idea of separating discussions of charisma from discussions of transformational leadership seems to be supported by other researchers, as there is apparently little evidence to suggest that the constructs of transformational leadership and charismatic leadership are one and the same (e.g., Yukl, 1999) and in fact some have found high 
inter-correlations among the factors of transformational leadership in contrast to the relatively low inter-correlations for the factors in charismatic leadership (e.g., Rowold and Heinitz, 2007). Nevertheless, the sheer breadth of transformational leadership studies, which include charisma as a major component, suggests that charisma as a construct will, for the time being, continue to be linked to transformational leadership in such a way that it may be difficult for future studies to examine charisma independently, without the need to refer to transformational leadership at least in passing.

\section{Implicit Leadership Theories}

"Without followers there can be no leaders" is nowhere more relevant than in the study of ILTs. The origins of ILT research, which examines leadership almost exclusively from the follower point of view, is generally credited to Eden and Leviatan (1975), who conceived of an "implicit organization theory," which they believed would be comprised of individuals' perceptions of organizational variables. This cognition based theory was not unique: implicit personality theory (Norman and Goldberg, 1966) had some years before hypothesized that the common factor structure observed in responses to a trait questionnaire was due in fact to some shared personality characteristics among the respondents.

Cognitive categorization theory would soon afterward posit that, in our limited capacity to attend to and process information quickly, people create prototypes or schemas as a means of easing cognitive load (Rosch, 1978). These ideas culminated in the leadership categorization theory put forth by Lord and his colleagues (e.g., Lord, Foti, and Phillips, 1982), which would eventually become the basis for the idea that ILTs are schemas, or mental models, of leadership that are accessed when necessary to classify people as leaders or non-leaders (Lord, Foti, and De Vader, 1984). These leadership prototypes are believed to be formed in part through exposure to social images (e.g., television, books, everyday stimuli), interpersonal interactions (e.g., parents, organized groups), as well as prior experiences with formal leaders (e.g., teachers, job supervisors); (Epitropaki and Martin, 2004; Nye and Forsythe, 1991; Hunt, Boal, and Sorenson, 1990).

Engle and Lord (1997) have suggested that the greater the degree of harmony between leader and follower, the more likely that the quality of the relationship is increased, as identification with the leader facilitates a common understanding and better social interactions. Epitropaki and Martin (2005) found that the closer the 'match' between the employees' perceptions of leadership and the managers' behaviors, the better the reported quality of Leader Member Exchange Theory (LMX); focuses on increasing organizational success by creating positive relations between the leader and subordinate. Increased quality-of-relationship has also been linked to increased follower satisfaction as well as reduced turnover (Hunt, Boal, and Sorenson, 1990).

Additionally, it has also been proposed that newcomers to an organization possess different ILTs than current employees, which could influence their expectations about leadership. In such cases, a mismatch between newcomer expectations and leader behaviours may result in work dissatisfaction and quick turnover (Offerman et al., 1994; 
Engle and Lord, 1997). Assessment of ILTs in organizations could help to inform leadership training designed to steer followers towards more realistic (or more organizationally aligned) evaluations of their leaders. In turn, this could reduce negative biases of leader behavior and produce more accurate (and therefore more valuable) performance assessments of leaders by their subordinates (Schyns and Meindl, 2005).

\section{Implicit Leadership Theories Questionnaire}

This is the most commonly used scale to measure the characteristic of 'a leader in a business setting'. Usually participants are asked to rate the leader on a 5-point scale (ranging from not at all characteristic to extremely characteristic). The scale is comprised of 8 dimensions (with observed internal consistency reliability estimates): Attractiveness (4 items: well-groomed, attractive, well-dressed, classy); Charisma (5 items: energetic, charismatic, inspiring, enthusiastic, dynamic); Dedication (4 items: dedicated, motivated, hard-working, goal-oriented); Intelligence (6 items: intellectual, educated, intelligent, wise, knowledgeable, clever); Masculinity (2 items: masculine, male); Sensitivity (8 items: sympathetic, sensitive, compassionate, sincere, warm, forgiving, understanding, helpful); Strength (2 items: strong, bold); and Tyranny (10 items: domineering, pushy, dominant, obnoxious, manipulative, power-hungry, conceited, loud, selfish, demanding) (Offerman, et al., 1994).

\section{Methodology}

Four leaders (two males managers and two females managers) were discussed with 5 followers each (direct reports). Out of these 20 followers; 10 were females and 10 males. Their ages varied from 25 to 45 . The average work experience each follower had with their leaders was 3.5 years.

Twenty minutes were spent with each respondent to discuss the leaders' behavior based on the 8 dimensions identified by Offerman, et al.(1994). Specific accounts were discussed to highlight how each leader was on the Attractiveness (4 items: well-groomed, attractive, well-dressed, classy); Charisma (5 items: energetic, charismatic, inspiring, enthusiastic, dynamic); Dedication (4 items: dedicated, motivated, hard-working, goaloriented); Intelligence (6 items: intellectual, educated, intelligent, wise, knowledgeable, clever); Masculinity (2 items: masculine, male); Sensitivity (8 items: sympathetic, sensitive, compassionate, sincere, warm, forgiving, understanding, helpful); Strength (2 items: strong, bold); and Tyranny (10 items: domineering, pushy, dominant, obnoxious, manipulative, power-hungry, conceited, loud, selfish, demanding). The aim of these interviews was to ascertain whether there was a difference in opinion and perception between the male followers and female followers regarding their leaders.

\section{Interviews}

Interviews were clustered into 4 profiles. The leaders have been given aliases of A, B, $\mathrm{C}$ and $\mathrm{D}$. Manager $\mathrm{A}$ is male with more than 15 years of experience, and his followers comprise of three females and two males. Manager B is a female with 12 years of 
experience with followers comprising of four males and one female. Manager $\mathrm{C}$ is a female with more than 13 years of experience her subordinates comprise of three females and two males. Lastly, Manager $D$ is a male with more than 15 years of experience and his team comprises of three females and two males. The description is given below.

\section{Profile 1 - Manager A}

Manager $\mathrm{A}$ is a leader at a large pharmaceutical company based in Karachi. He has more than 15 years of experience. Five followers were selected from his team; out of which three were females and two males. The figure 1 shows the opinions of the respondents both males and females on the following eight dimensions. On attractiveness, females rated their manager a 4.67 on a scale of 5 whereas the males rated 3.00 on a scale of 5 ; on the Charisma dimension females rated a 4 out of 5 whereas the males rated a 3.50 out of 5 ; on the Dedication dimension the females rated 3.67 on a scale of 5 whereas the males rated a 3.00 ; Intelligence; females rated their manager a 3 whereas the males rated a 4 on the scale of 5 ; on the Masculinity dimension the females rated their manager a 3 and the males rated 2 on the scale of 5 ; Sensitivity was given a 4 by the female followers whereas the males rated a 3; on the Strength dimension both the followers rated the leader a 3.00 on the scale of 5 ; and finally on Tyranny the female followers gave a 4.33 and the males gave a 4.00 on the scale of 5 .

According to female respondents the leader scored a 4.7 on a scale of 5 on attractiveness dimension and during the interview they said that they found the manager attractive and well dressed which had an impact on the organizational culture as the followers also tried to dress properly and be classy. However, the male respondents gave the manager A 3 out of 5 on attractiveness, barely average and they said that there was nothing extraordinary in the way the manager dressed. As pointed out in earlier researches this instrument does not control bias (e.g., Avolio, Yammarino and Bass, 1991). The opinions of the respondents again clashed on the Masculinity dimension where the female respondents gave a higher ranking ( 3 out of a scale of 5 ) to the manager as compared to the male counterparts (2 out of 5 ).

During interview sessions, the following phrases were used for Manager A:

1) Motivates workers by setting examples(female respondent)

2) Asks the opinions of others before making decisions (female respondent)

3) The manager uses fear tactics to get work done in the workplace (Male respondent)

4) Dresses well to encourage others to dress well (female respondents)

5) Presents our work as his own to the seniors (male respondent)

6) Does not create an environment of trust (male respondent) 


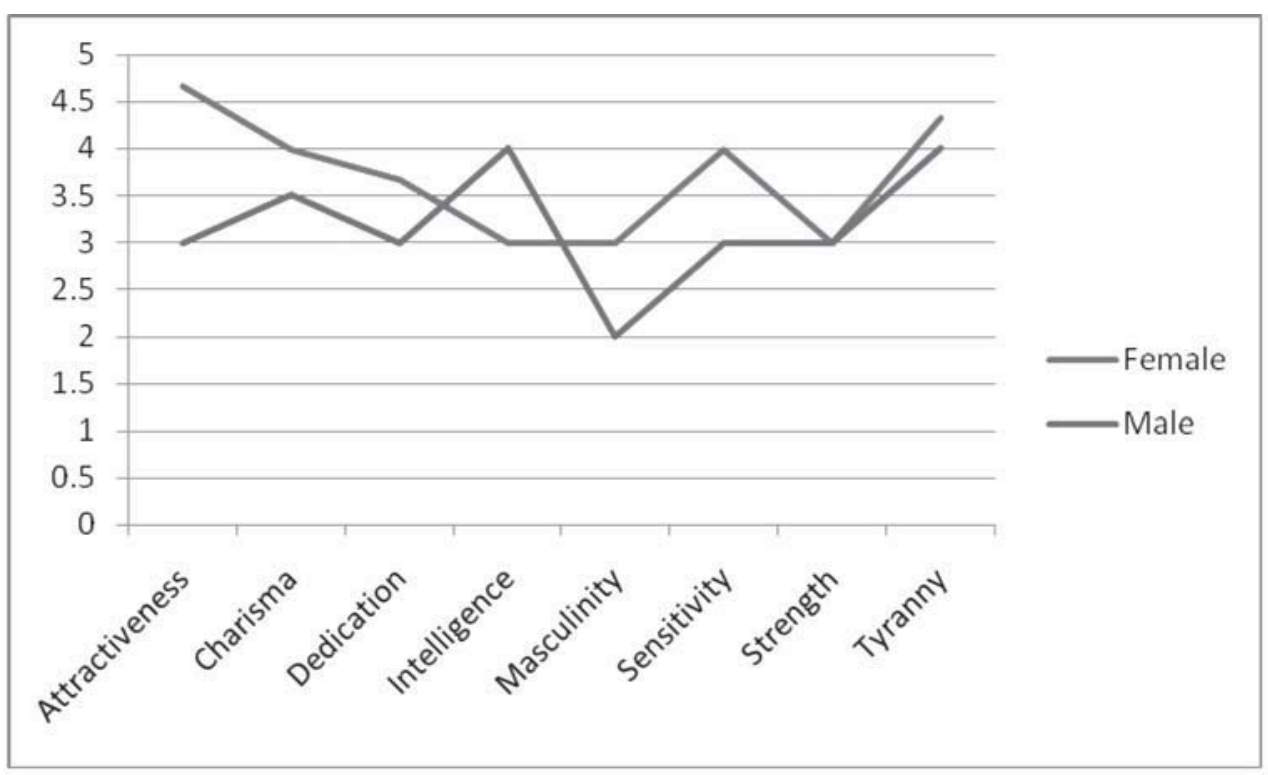

Figure 1: Respondents' opinion on the 8 dimensions for Manager A

\section{Profile 2 - Manager B}

Manager B is a female with 12 years of experience working in a bank with followers comprising of four males and one female. The figure 2 shows the opinions of the respondents both males and females on the following eight dimensions. On attractiveness, according to females they rated their manager a 3.00 on a scale of 5 whereas the males rated 4.00 on a scale of 5 ; on the Charisma dimension females rated a 4 out of 5 whereas the males rated a 3.50 out of 5 ; on the Dedication dimension the females rated 4.00 on a scale of 5 where as the males rated a 3.75 ; Intelligence; females rated their manager a 3 whereas the males rated a 3.75 on the scale of 5 ; on the Masculinity dimension the females rated their manager a 4 and the males rated 4.75 on the scale of 5; Sensitivity was given a 3 by both the followers; on the Strength dimension both the followers rated the leader a 3.00 on the scale of 5 ; and finally on Tyranny the female followers gave a 5 and the males gave a 4.00 on the scale of 5 . According to the female respondents the female manager scores high of the Tyranny dimension with 5 out of 5 as compared to the male followers who gave the manager an average of 4 out 5 . Interestingly this perception negates the concepts of transformational leadership. Since earlier research has always concluded that females are considered to be more of change agents and role models, however this research shows that according to the perceptions of the subordinates the female leaders are considered tyrannical. Similarly on the Masculinity dimension male followers gave her a 4.75 out of 5 as compared to the female followers who gave the manager a 4 out of 5.

During the interview, following statements were made for the manager:

1) The manager is bossy and forces work on us (female respondent) 
2) When the work is not done she becomes obnoxious (male respondent)

3) The manager is power hungry and pushy (male respondent)

4) She boldly favors the team (male respondent)

5) Treats all equally (female respondent)

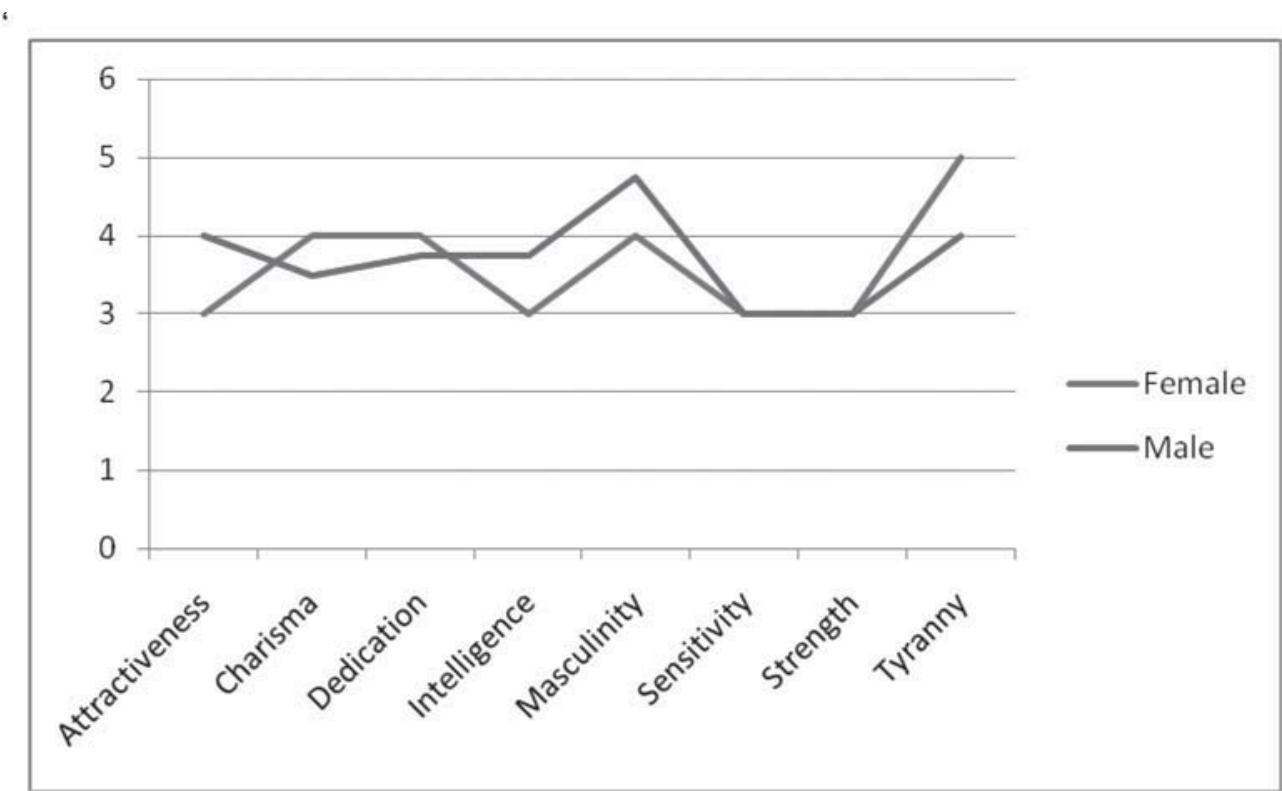

Figure 2: Respondents'opinion on the 8 dimensions for Manager B

\section{Profile 3 - Manager C}

Manager $C$ is a female working in a training consultant firm with more than 13 years of experience. Her subordinates comprise of three females and two males. Figure 3 shows the opinions of the respondents both males and females on the following eight dimensions, Attractiveness, according to females they rated their manager a 3.00 on a scale of 5 whereas the males rated 4.00 on a scale of 5 ; on the Charisma dimension females rated a 3.33 out of 5 whereas the males rated a 4.50 out of 5 ; on the Dedication dimension the females rated 4.00 on a scale of 5 where as the males rated a 4.50 ; Intelligence; females rated their manager a 3 whereas the males rated a 4 on the scale of 5; on the Masculinity dimension the females rated their manager a 2.67 and the males rated 3 on the scale of 5 ; Sensitivity was given a 3.67 by the female followers whereas the males rated a 4; on the Strength dimension the females rated the leader a 3 and the male followers a 3.50 on the scale of 5; and finally on Tyranny the female followers gave a 4.00 and the males gave a 4.50 on the scale of 5 . Again the bias couldn't be controlled in this case since the male followers rated their female leader higher on almost all the eight dimensions. 


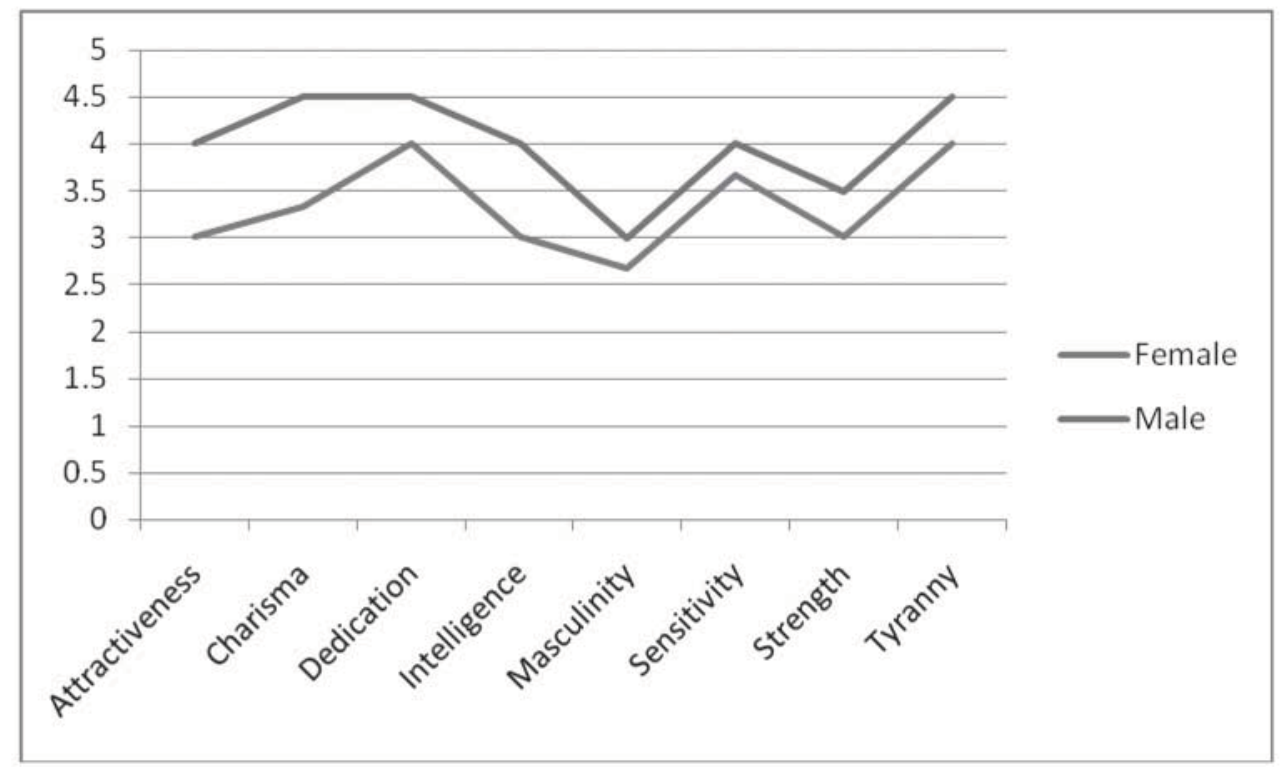

Figure 3: Respondents opinion on the 8 dimensions for Manager C

During the interview, the respondents made the following comments about their leader:

1) Madam dresses very professionally and expects all of us to do the same(Male respondent)

2) She is very strict on deadlines and aggressive if work is not done on time (Male respondent).

3) Madam is always the first in the office and very punctual (Male respondent and female respondent)

4) She is a team player but does not give us feedback once the work is completed (male and female respondent)

5) She encourages new ideas and helps to execute them (Male respondent)

\section{Profile 4 - Manager D}

Manager $D$ is a male with more than 15 years of experience working in an advertising agency and his team comprises of three females and two males.

The figure 4 shows the opinions of the respondents both males and females on the following eight dimensions, Attractiveness, according to females they rated their manager a 4.00 on a scale of 5 whereas the males rated 2.00 on a scale of 5 ; on the Charisma dimension females rated a 3.67 out of 5 whereas the males rated a 3.50 out of 5 ; on the Dedication dimension the females rated 2.00 on a scale of 5 where as the males rated a 3.00 ; Intelligence; both the followers gave a 4 out of 5 ; on the Masculinity dimension the females rated their manager a 3.67 and the males rated a 3.00 on the 
scale of 5 ; Sensitivity was given a 4 by the female followers whereas the males rated a 2; on the Strength dimension both the followers rated the leader a 4.00 on the scale of 5; and finally on Tyranny both the followers gave a 3.00 on the scale of 5 . This profile was interesting as both the respondents were on the same page regarding their perceptions of their leaders. However the data is not enough to create a generalizable statement.

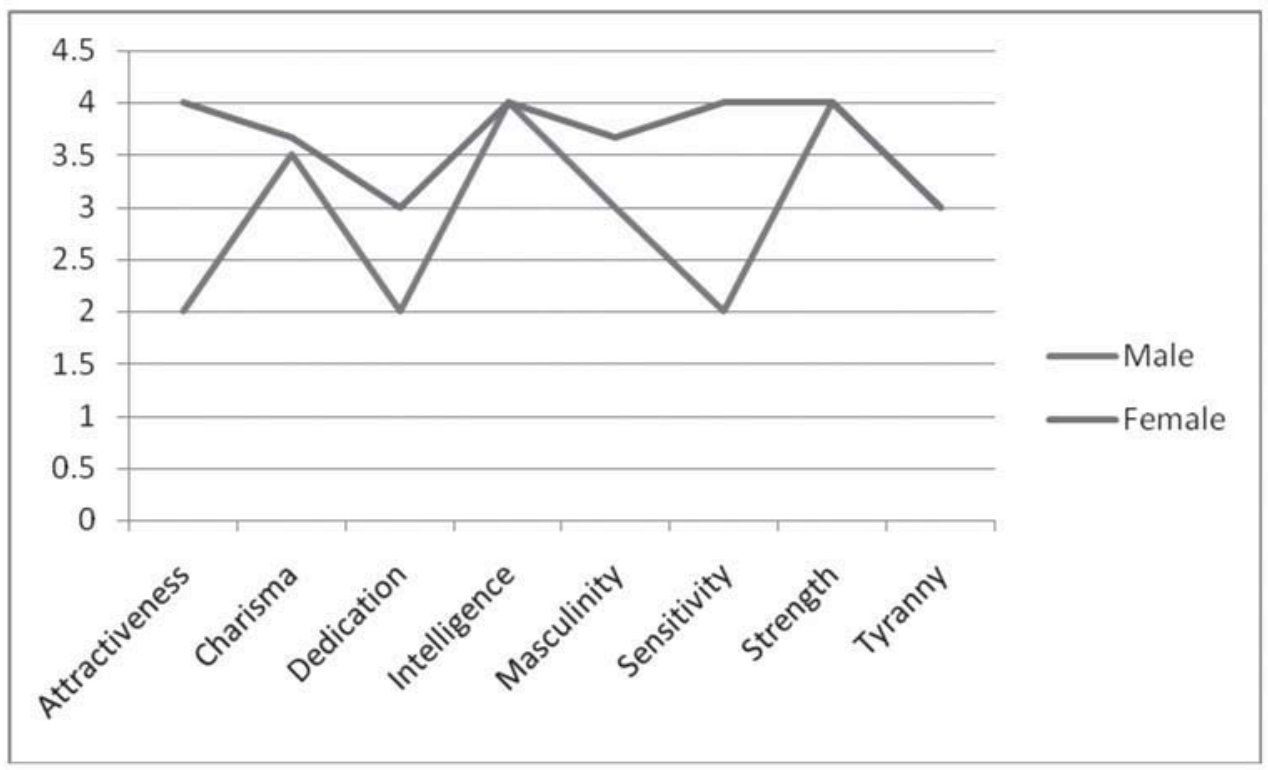

Figure 4: Respondents opinion on the 8 dimensions for Manager D

During the interview the respondents made the following comments about their leader:

1) Our manager is never on time and expects us to be there on time, its not fair (male and female respondents)

2) $\mathrm{He}$ is more considerate towards the female workers as compared to us (male respondents)

3) He is not too ambitious but does not take any responsibility (male and female respondents)

4) He dresses well and expects others to follow suit (female respondents).

5) The manager is an intelligent individual who knows how to get work done (males and female respondents).

\section{Conclusion and Recommendations}

This research has limitations since the sample size is small. There is also a need for further analysis using the behavioural model of implicit theories. This research only focuses on the perceptions of the followers on the eight dimensions identified by 
Offerman, et al., (1994). Interesting observations and comments were made by respondents regarding the language used in the ILT scales, as apparently there were quite a few words which perhaps did not translate very precisely, even for native speakers these terms can be confusing. An example of this includes the term "clever," which generally means smart and creative (which is good) but is also sometimes used with additional connotation of sneakiness or craftiness (which is not necessarily good). Other examples include "dynamic," which can either mean "moving towards change" (good) or "forceful" (not so good) or "moving toward change" (better), and "strong," which can refer to either physical or mental capacities. Therefore a scale should be developed that uses words that would be understood clearly. 


\section{References}

Avolio, B. J., Bass, B. M., and Jung, D. I. (1999), 'Re-examining the components of transformational and transactional leadership using the Multifactor Leadership Questionnaire', Journal of Occupational and Organizational Psychology, Vol. 72, pp. 441-462.

Avolio, B.J., Yammarino, F.J., and Bass, B.M. (1991), Identifying common method variance with data collected from a single source: An unresolved sticky issue. Journal of Management, Vol. 17, pp. 571-587

Bass, B. M. (1985), Leadership and Performance Beyond Expectations. New York, NY: Free Press.

Bass, B. M. (1988), The inspirational process of leadership. Journal of Management Development, Vol. 7,

pp. 21-31.

Bass, B. M., and Avolio, B. J. (2000), MLQ Multifactor leadership questionnaire. Redwood City: Mind Garden.

Bass, B.M., and Avolio, B.J. (1990a), Developing transformational leadership: 1992 and beyond. Journal of European Industrial Training, Vol. 14, pp. 21-27.

Bass, B.M., and Avolio, B.J. (1990b), 'The implications of transactional and transformational leadership for individual, team, and organizational development,' in W. Pasmore and R.W. Woodman (Eds), Research in Organizational Change and Development, Vol. 4 (pp. 231-272). Greenwich, CT:JAI Press.

Bryman, A. (1992), Charisma and leadership in organizations. Newbury Park, CA: Sage

Burns, J. M. (1978), Leadership, New York, NY: Harper and Row

Eden, D. and Leviatan, U. (1975), Implicit leadership theory as a determinant of the factor structure underlying supervisory behavior scales. Journal of Applied Psychology, Vol. 60, No. 6, pp. 736-741

Engle, E. M. and Lord, R. G. (1997), Implicit theories, self-schemas, and leader-member exchange. Academy of Management Journal, Vol. 40 No. 4, pp. 988-1010.

Epitropaki, O. and Martin, R. (2004), Implicit leadership theories in applied settings: Factor structure, generalizability, and stability over time. Journal of Applied Psychology, Vol. 89 No. (2), pp. 293-310.

Epitropaki, O. and Martin, R. (2005), From ideal to real: A longitudinal study of the role of implicit leadership theories on leader-member exchanges and employee outcomes.

Journal of Independent Studies and Research - MSSE

Volume 8

Number 1

January 2010 239 
Journal of Applied Psychology, Vol. 90, No. 4, pp. 659-767.

Hunt, J. G., Boal, K. B., and Sorenson, R. L. (1990), Top management leadership: Inside the black box. Leadership Quarterly, Vol. 1 No. 1, pp. 41-65.

Komives, S. R. (1991). Gender differences in the relationship of hall directors' transformational and transactional leadership and achieving styles. Journal of College Student Development, 32, 155-165.

Lord, R. G., Foti, R. J., and De Vader, C. L. (1984). A test of leadership categorization theory: Internal structure, information processing, and leadership perceptions. Organizational Behavior and Human Performance, Vol. 34 No. 3, pp. 343-378.

Lord, R. G., Foti, R. J., and Phillips, J. S. (1982), A theory of leadership categorization. In J. G. Hunt, U. Sekeran, and C. Schriesheim (Eds.), Leadership: Beyond establishment views. Carbondale, IL: Southern Illinois University

Norman, W. T. and Goldberg, L. R. (1966), Raters, ratees, and randomness in personality structure. Journal of Personality and Social Psychology, Vol. 4 No. 6, pp. 681-691

Nye, J. L. and Forsythe, D. R. (1991), The effect of prototype-based biases on leadership appraisals: A test of leadership categorization theory. Small Groups Research, Vol. 22, pp. 360-379.

Offerman, L. R., Kennedy, Jr., J. K., and Wirtz, P. W. (1994), Implicit leadership theories: Content, structure, and generalizability. Leadership Quarterly, Vol. 5, No. 1, pp. 43-58.

Rosch, E. (1978), Principles of categorization, in B. B. Lloyd (Ed.), Cognition and categorization. Hillsdale, NJ: Lawrence Erlbaum

Rowold, J. and Heinitz, K. (2007), Transformational and charismatic leadership: Assessing the convergent, divergent and criterion validity of the MLQ and CKS. Leadership Quarterly, Vol. 18, pp. 121-133.

Rush, M. C. Thomas, J. C, \& Lord, R. G. (1977). Implicit leadership theory: A potential threat to the internal validity of leader behavior questionnaires. Organizational Behavior and Human Performance, 20(1), 93-110

Schyns. B. and Meindl, J. R. (2005), Implicit leadership theories: Essays and explorations. Greenwich, CT: Information Age Publishing.

Yukl, G. (1999), An evaluation of conceptual weaknesses in charismatic and transformational leadership theories. Leadership Quarterly, Vol. 10 No. 2, pp. 285-305. 


\section{APPENDIX}

For each trait below please use the following scale to indicate the extent to which it should describe an ideal leader in a business setting

\begin{tabular}{|c|c|c|c|c|c|}
\hline \begin{tabular}{|l}
1 \\
Not at all \\
characteristic
\end{tabular} & $\begin{array}{c}2 \\
\text { Slightly } \\
\text { characteristic }\end{array}$ & \multicolumn{2}{|c|}{$\begin{array}{c}3 \\
\text { Moderately } \\
\text { characteristic }\end{array}$} & $\begin{array}{c}4 \\
\text { Characteristic }\end{array}$ & $\begin{array}{c}5 \\
\text { Extremely } \\
\text { characteristic }\end{array}$ \\
\hline Sympathetic & 1 & 2 & 3 & 4 & 5 \\
\hline Energetic & 1 & 2 & 3 & 4 & 5 \\
\hline Dedicated & 1 & 2 & 3 & 4 & 5 \\
\hline Well groomed & 1 & 2 & 3 & 4 & 5 \\
\hline Domineering & 1 & 2 & 3 & 4 & 5 \\
\hline Masculine & 1 & 2 & 3 & 4 & 5 \\
\hline Intellectual & 1 & 2 & 3 & 4 & 5 \\
\hline Strong & 1 & 2 & 3 & 4 & 5 \\
\hline Sensitive & 1 & 2 & 3 & 4 & 5 \\
\hline Charismatic & 1 & 2 & 3 & 4 & 5 \\
\hline Motivated & 1 & 2 & 3 & 4 & 5 \\
\hline Attractive & 1 & 2 & 3 & 4 & 5 \\
\hline Pushy & 1 & 2 & 3 & 4 & 5 \\
\hline Educated & 1 & 2 & 3 & 4 & 5 \\
\hline Bold & 1 & 2 & 3 & 4 & 5 \\
\hline Compassionate & 1 & 2 & 3 & 4 & 5 \\
\hline Inspiring & 1 & 2 & 3 & 4 & 5 \\
\hline Hard working & 1 & 2 & 3 & 4 & 5 \\
\hline Well dressed & 1 & 2 & 3 & 4 & 5 \\
\hline Dominant & 1 & 2 & 3 & 4 & 5 \\
\hline Intelligent & 1 & 2 & 3 & 4 & 5 \\
\hline Obnoxious & 1 & 2 & 3 & 4 & 5 \\
\hline Enthusiastic & 1 & 2 & 3 & 4 & 5 \\
\hline Goal oriented & 1 & 2 & 3 & 4 & 5 \\
\hline Classy & 1 & 2 & 3 & 4 & 5 \\
\hline Manipulative & 1 & 2 & 3 & 4 & 5 \\
\hline Wise & 1 & 2 & 3 & 4 & 5 \\
\hline Sincere & 1 & 2 & 3 & 4 & 5 \\
\hline Dynamic & 1 & 2 & 3 & 4 & 5 \\
\hline Power Hungry & 1 & 2 & 3 & 4 & 5 \\
\hline Knowledgeable & 1 & 2 & 3 & 4 & 5 \\
\hline Warm & 1 & 2 & 3 & 4 & 5 \\
\hline Conceited & 1 & 2 & 3 & 4 & 5 \\
\hline Clever & 1 & 2 & 3 & 4 & 5 \\
\hline Forgiving & 1 & 2 & 3 & 4 & 5 \\
\hline Loud & 1 & 2 & 3 & 4 & 5 \\
\hline Selfish & 1 & 2 & 3 & 4 & 5 \\
\hline Male & 1 & 2 & 3 & 4 & 5 \\
\hline Understanding & 1 & 2 & 3 & 4 & 5 \\
\hline Helpful & 1 & 2 & 3 & 4 & 5 \\
\hline Demanding & 1 & 2 & 3 & 4 & 5 \\
\hline
\end{tabular}

Journal of Independent Studies and Research - MSSE

Volume $8 \quad$ Number 1

January 2010 241 